\title{
Classes for gifted children as a development factor of self-awareness in primary school
}

\author{
Phd Alla Gudzovskaya \\ Senior researcher at the Institute for Research on Social Phenomena, Samara, Russia \\ Phd Marina Mishkina \\ Professor of Social Psychology at Samara National Research University, Samara, Russia
}

\begin{abstract}
The article dwells on the issue of self-awareness development in primary schools. The paper offers theoretical and empirical researches of the issue. The empirical research is based on Newtten's method of "unfinished ideas" (modified by A.B. Orlov); Newtten's the scale of temporary settings; self-appriciation method "Tree" or "Find yourself" (modified by L.P. Ponomarenko); content-analysis of the composition "I am a human being". In conclusion the article provides pedagogical recommendations to a constructive development of self-awereness of pupils. The article was written with the support of Russian Humanitarian Scientific Foundation, project 15-0610726 (a).
\end{abstract}

Keywords: self-awereness, giftedness, self-appriciation, personal attitude, psychology of primary pupils.

\section{Introduction}

Self-awareness is a psychological form of personality that is a number of relations and ideas about itself, its role and position in the world, appreciation of its activities. Self-awareness lies in the basis of organization and regulation of a person's life. There are a lot of researches particularly by I.S. Kont, V.V. Stolin, I.I. Cheshokova, K. Horney, E.E. Erickson, V.A. Yadov, etc. devoted to the analysis peculiarities of self-awareness.

System-forming and integrative core of individuality and self-awareness is self-appriciation of personality, which mostly makes life positions of a person, the level of his/her demands. The origins of the ability to appreciate yourself are set in the early childhood, whereas the development and improvement of individuality and self-awareness continues during the whole life of a person.

Psychologists consider such factors as a communication with the surrounding and the very activities of a child as the main conditions of development of and self-awareness. Forms, kinds and criteria of appreciation are used during the communication, whereas their testing and fulfilling of personal sense take place in the individual experience. The child chooses criteria and methods of appreciating another person, he/she copies those methods from other people, from the way others appreciate him/her. The formation of an adequate self-appriciation as one of the individual peculiarities of a person is closely connected to the issues of treating, teaching and development (I.M. Kon, A.I. Lipkina, V.S. Mouhina, L.F. Obuhova, R.V. Ovcharova, D.B. Elkonin).

\section{The concept of self-appriciation}

Self-appriciation - the most important personal instance - greatly affects all spheres of a person's life activity. It is a kind of regulator that contributes to self-development. The level of demands, energy of a person his/her relations with other people depend on the peculiarities of self-appriciation [11].

According to the official statistic data, by the time children begin to study at school $30 \%$ of them already have social adaptation issues. Most of those children do not determine the idea of themselves as valuable [10]. 
A child of 7-10 years old spends most of his/her time in school, thus, studying becomes his/her main activity. In this case, the most powerful factor that can affect child's self-appriciation is the appreciation of a teaher. A child who takes teacher's point of view into the consideration, asses him/herself and the other classmates as "excellent" and "unsatisfactory", in other words, divides them into "good" or "bad" pupils $[3 ; 4 ; 5 ; 6 ; 7 ; 8]$.

There is a number of theoretical and empirical researches on relationship between success in the main activity (for junior pupils - in studying) and peculiarities of the attitude to the world. The conception of J. Newtten proves the importance of such side of attitude to the world as the temporary transspective of life. Newtten offers facts of the relationship between lifestyle conditions and the perspective of the future $[5 ; 6 ; 10 ; 7]$.

M.R. Ginsburg relates an attitude to somebody's life periods to the factors of self-definition, which may be harmonic or may demand pedagogical or even psychotherapeutic correction [1].

Unofficial practice of differential teaching can be found in many educational establishments. It is based on the practical records of a child who enters the school or during the first years of studying. Mary-Catherine McClain and Steven Pfeiffer after conducting a national survey have reported about significant changes in the definitions and categories of giftedness over the past decade, and the variability of identification methods of giftedness [7]. They claim that nowadays there is not any country that supports only one model of definition of childhood giftedness; that is because administrators think that the whole rocess is mostly random. Another scholar, Nada Puric, comes to the conclusion that $50 \%$ of success at school can be explained by intellectual factors. The rest of academic success depend on personal characteristics, motivation, social and material status, cultural and educational status of the family [13]. The question is in what way it affects the children when they are being differentiated as "gifted", "normal" and "weak"?

\section{Hypothesis}

While planning the empirical research, we supposed that children who study in the classes for the "gifted" have a higher level of self-appriciation, they want to become leaders and they understand the world as something valuable and they wish to be a part of it for a long time (have a long timetranspective). The pupilsfrom other classes think of themselves less positively, the ideas of the world and their place in it are simpler and less valuable, their timetransspective is shorter.

\section{Method}

The research was based on the following methods: J. Newtten's "unfinished ideas" (modified by A.B. Orlov); Newtten's the scale of temporary settings; self-appriciation method "Tree" or "Find yourself" (modified by L.P. Ponomarenko); contentanalysis of the composition "I am a human being" [2].

\section{Course of the experiment}

The survey was held in one of the authoritative grammar schools in Samara (Russia) during the second term of the academic year. 40 third-grade pupils took part in it. All classes were divided into two groups. 17 pupils were put in "the most successful" group (experimental group) and the rest 27 pupils joined the testing group.

\section{Results}

The analysis of the results showed that each group had different aspects of self-awareness. Children from the experimental group are interested in goals that are connected with leadership, relaxation and entertainment ( $70 \%$ of pupils). Pupils from the tasting group are more concentrated on overcoming difficulties (74.1\%).

The most popular features of attitude to themselves of junior pupils of the perspective group are the positions aimed to leadership, rest and entertainment (70 and $71.4 \%$ of questioned pupils correspondingly; the "Tree" method). As for the pupils in the testing group the most, the most characteristic settings are ones that aimed to overcome difficulties and to reach a goal (74.1 and $54.1 \%$ of questioned pupils of the testing and experimental groups correspondingly).

\section{Discussion}

The groups are different because of the different number of pupils who defined their state as "comfortable", "normal/adaptive". In the class formed by the idea of "all the rest" there are half of such pupils $(48.1 \%)$ in experimental group - only every fifth (21.4\%). 
One of the tasks for the third grade pupils was to define a figure on the picture they did not like. The results cleared up the differences between the groups towards the denied aspects of self-attitude. In the class of low social status the dominative unpleasance of negative emotional state - mainly "crisis state" (33.3 \%) is marked, "tiredness, general weariness, little store of force, shyness" (33\%). $22.2 \%$ of pupils defined "higher self-apriciation with the setting to lesdership" as negative.

In psychology (for example, in psychoanalysis) rejected emotions are explained like pushing some modern tendencies out. Thus, in the testing group it is possible to predict hupothetically the development of negative tendencies of self-attitude, and in the experimental group - growing contradictions between the setting to leadership and aiming to entertainments and wishes to find an easy way to success.

We have analysed corresondence of projective self-appriciation of students (figure "l") and ideal appreciation (figures that are liked). In the prestige class the real image "I" coinsides with the ideal one mush more often $(71 \%$ of questioned pupils of the experimental group and $41 \%$ in the testing group). In that age a high self-apriciation is typical. That is why it is possible to say about a worrying tendency in a testing group, where more than a half of students demonstrate rejection of themselves and their social status.

Attitude to themselves is clearly shown in the composition "I am a human being". In the group of "gifted pupils" $61 \%$ of children identify themselves as representatives of human society. That shows positive dynamics of their personal development. In the other group one third of the questioned pupils do not relate themselves to human society and write about their individual charactiristics. In the experimental group there are only $8 \%$ of such students.

Attitude to themselves is also shown in the characteristics and categories that pupils use to describe themselves. L.V. Vygodsky after analyzing a lot of children's came to the conclusion that the more words and categories they use, the more they orient in the topic. In the experimental group children used from 8 to 69 words, in the testing group - from 5 to 43.

Attitude to studying activity, the learning process, school, teachers and classmates is reflected in the results of two diagnostic procedures: Newtten's "Unfinished ideas" and the composition "I am a human being".

In the composition the theme on teaching and cognitive interests is not given, that is why the presence of studying categories in the text accurately shows the factor of significance and importance of the topic for the author. In the experimental group $92 \%$ of the pupils were interested in studying and cognition. In the testing group $56 \%$ of pupils have the same interests.

The middle number of the used categories, showing cognitive interest in experimental and testing groups was revealed: 3.8 and 1.5 categories correspondingly. In the group for the gifted the part of studying-cognitive category among all categorical units is $17 \%$. At the same time, in the testing group this part is only $6 \%$ (differences are important at the level of importance of $p=0,001)$.

For revealing some attitudes to the world in the compositions of third-graded pupils the parts of the usage of category «Social World» were calculated. To this group of categories the following aspects were related like people, friends, parents, world (mankind), social roles.

In the experimental group $46,2 \%$ of asked pupils relate to the categories of social world in their compositions that shows the importance of different sides of the world for the author. The part of this category relating to the whole volume of the texts is $13,2 \%$. In the testing group «world» is shown less picturesquely. In this group $29,6 \%$ of pupils used categories of outer world (differences are little), the part of categories to the whole volume of compositions - 6,5\% (differences are little at the level of significance of $p=0,001$ ). According to A.Adler, social interest is the necessary condition of psychological health.

Descending of social interest may be caused by psychological tension, stress.

The scale of temporary settings of $\mathrm{J}$. Newtten let reveal that in the group for talented pupils appreciations of criterion inner / outer control are close to the boundary of value «outer control» (4,3 b.). This means that for them past is a period of life the process and results of which depended upon not them, but other people. The middling mark of that aspect in the testing group is on the contrary, lower than normal $(3,1 \mathrm{~b}$.). In other words, pupils from the «usual» group think, that past depended on their efforts, in fact they witness their responsibility and, perhaps, fault for the sticking nickname «usual» to them. 
In the testing group the value and positiveness of future are shown less than in the experimental group, though about presence tendencies were contradictive. This result also demands analysis and interpretations.

Hypothesis of research is partly sured. The junior students who are taught in the group for perspective talented children have got higher self-appreciation, position to leadership, they see the world being actual, worth, and significant. The thirdgrade pupils from the parallel group appreciate themselves less positively, their ideas about the world and themselves are simpler, they see the world like less actual and worth one.

The expecting difference in the longitude of life perspective among the pupils of different groups is not revealed.Thus, success in studying activities of junior pupils, attitude of the teacher shown to pupil and his / her temporaries affect selfcoinside of a child, his / her self-appreciation, social status, attitude to the world, other people, own life transspective.

Behaviorist attitude towards the separation of groups into successful (the so-called «prestige», for talented people) and unsuccessful (for «usual» children) may be considered like a positive sureness for those children (as well as their parents, teachers), who were taken into the group of «perspective», if not to take into consideration surroundings of less successful temporaries.

Is studying in groups for «usual» children negative sureness that makes escape behavior taking into that group?

This question cannot be answered positively. In case when a pupil is moved from the group for talented students into a «usual» one, he / she gets not a one-time negative sureness, but a «long-life» one, which he / she can get rid of with great difficulties or even it is impossible to do by himself / herself. In the school, as a rule, there is not a process of ecological, friendly «moving from group to group depending upon the level of success of studying, testing» (among the parallel); as a result, the juniors have to adopt to the position of outsiders for the nearest 8-10 years.

The study highlights the difficulties of gifted children education and the resultant social situation around this training. Different countries face the same problem: a better development of abilities becomes possible in specialized classes, however, along with academic success come problems of psychological nature, which are widely explained by Brazilian researchers Vanessa Terezinha and Alves Tentes[14], and a scientist from Hungary, Eva Gyarmathy [6].

\section{Conclusion}

The data of our work as a result are useful for school psychologists while choosing of effective direction in working with children who have low social status. The aims of the programme must be normalization of social status and self-appreciation of pupils, resistance to the practice of differentiation of pupils according to criterion of successfulness of studying activity. The main goal of teacher-psychology is to prevent fixing of situational unpleasant state of a child into the quality of personality, that will be an important step on the way of forming psychologically healthy, active personality of a pupil.

\section{Bibliography}

[1] Ginzburg M.R. Psychological content of personal self-awareness // Questions of psychology. 1994. № 3. P. 4352.

[2] Gudzovskaya A.A. Content-analysis like a method of diagnostics of personal maturity / Acmeology: developing personality and professional. Set of labours - Samara: New technics. - 2005. P. 88-100.

[3] Gudzovskaya A.A., Myshkina M.S. The place of talent in social expecting of students. Social phenomena magazine of international research. 2016. № 6. P. 71-77.

[4] Gudzovskaya A.A., Pesina E.A., Proskurina A.A. Talent and Education / Main editor A,V, Nechaev. - Samara: GbOUvOSO «Samara State Region Academy (Nayanovoi)», 2016. 183 p.

[5] Gudzovskaya A.A., Proskurina A.A. The role of social expectances in revealing of creativity and talent // Psychology. Historical-critical observations and contemporary researches. 2015. № 6. P. 124-138.

[6] Gyarmathy E., The Gifted and Gifted Education in Hungary //Journal for the Education of the Gifted, January $11,2013$. 
[7] McClain M., Pfeiffer S., Identification of Gifted Students in the United States Today: A Look at State Definitions, Policies, and Practices// Journal of Applied School Psychology,28:59-88,2012

[8] Myshkina M.S. Perculiarities of expectations of teachers from colleques and pupils // Social phenomena magazine of international research. 2016. № 4. P. 33-41.

[9] Myshkina M.S. Representations of students-psychologists about social expectations of teachers and pupils // Social phenomena - magazine of international research. 2015. № 3. P. 88-93.

[10] Newtten J. Motivation, action and perspective of future / Edited by D.A. Leontjev. - M.: Smysl, 2004. 608 p.

[11] Perevoznikova E.V., Psychological perculiarities of self-awareness of teen-agers from the families of orthodox and atheistic orientation, 2004.

[12] Pozdnyakova O.L., Perculiarities of self-appreciation of children of junior age. 2003.

[13] Puric N., The Influence of Willing- Motivations Characteristics of Students on Their School Achievements // European Journal of Social Sciences Education and Research 2017-01 04, p.126-139.

[14] Terezinha V., Tentes A., Gifted Student and Underachievers: Prevalence, Characteristics, Preferences, Interests and Learning Styles // The 21st Biennial World Conference of the WCGTC Educating Gifted and Talented Children - Turning Research Into Practice Odense, Denmark, August 10-14, 2015. P.135. 